\title{
Hybrid Organic-Inorganic Coordination Complexes as Tunable Optical Response Materials
}

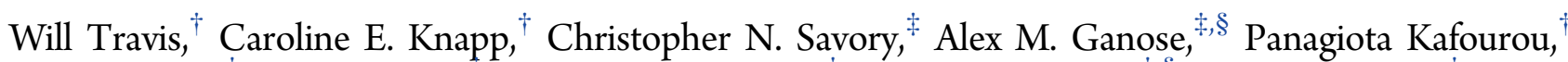
Xingchi Song, ${ }^{\dagger}$ Zainab Sharif,,$^{\dagger}$ Jeremy K. Cockcroft, ${ }^{\dagger}$ David O. Scanlon, ${ }^{\ddagger, \S}$ Hugo Bronstein, ${ }^{\dagger}$ and Robert G. Palgrave*, ${ }^{\dagger}$

${ }^{\dagger}$ Department of Chemistry and ${ }^{\ddagger}$ Kathleen Lonsdale Materials Chemistry, Department of Chemistry, University College London, 20 Gordon Street, London, WC1H 0AJ, United Kingdom

${ }^{\S}$ Diamond Light Source Ltd., Diamond House, Harwell Science and Innovation Campus, Didcot, Oxfordshire OX11 0DE, United Kingdom

\section{Supporting Information}

ABSTRACT: Novel lead and bismuth dipyrido complexes have been synthesized and characterized by single-crystal X-ray diffraction, which shows their structures to be directed by highly oriented $\pi$-stacking of planar fully conjugated organic ligands. Optical band gaps are influenced by the identity of both the organic and inorganic component. Density functional theory calculations show optical excitation leads to exciton separation between inorganic and organic components. Using UV-vis, photoluminescence, and Xray photoemission spectroscopies, we have determined the materials' frontier energy levels and show their suitability for photovoltaic device fabrication by use of electron- and hole-transport materials such as $\mathrm{TiO}_{2}$ and spiro-OMeTAD respectively. Such organic/ inorganic hybrid materials promise greater electronic tunability than the inflexible methylammonium lead iodide structure through variation of both the metal and organic components.

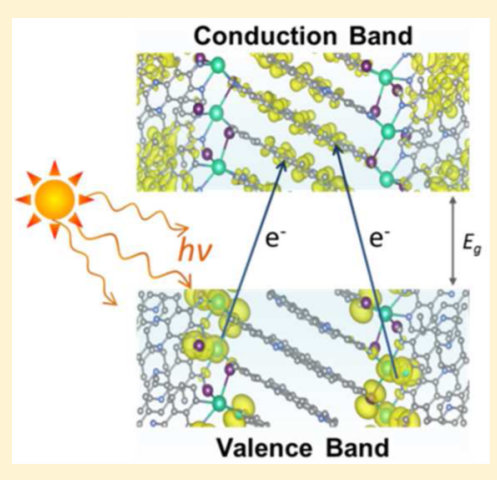

\section{INTRODUCTION}

Solar energy is regarded as perhaps the most promising alternative to fossil fuels. ${ }^{1}$ In recent years, solar cells based on hybrid organic-inorganic absorbers with perovskite structure have shown potential as an alternative to silicon solar cells. ${ }^{2}$ Perovskite solar cells already show efficiencies surpassing those of dye-sensitized, organic, and amorphous silicon solar modules. ${ }^{3}$ The archetypal perovskite solar cell absorber material is methylammonium lead(II) iodide $\left(\mathrm{CH}_{3} \mathrm{NH}_{3} \mathrm{PbI}_{3}\right.$ or MAPI) and has significant advantages over competing commercial and emerging technologies: synthesis is achieved from available and cheap starting materials via solution processes ${ }^{4}$ or scalable vapor-phase deposition methods, ${ }^{5}$ making possible large-scale industrial production. ${ }^{6}$ Furthermore, efficiencies of MAPI solar cells have exceeded $20 \%{ }^{4 b, 7}$ Such high efficiencies have been achievable due to MAPI's high optical absorption coefficient, excellent defect tolerance, ${ }^{8}$ ambipolar charge transport, ${ }^{9}$ and very long electron-hole diffusion lengths ${ }^{10}$ which result from high minority-carrier lifetime $(\tau)$ and mobility $(\mu) .{ }^{10 \mathrm{~b}, 11}$ An important factor in each of these properties is thought to be the three-dimensional (3D) connectivity of the inorganic (lead iodide) sublattice in the perovskite structure.

Despite these highly positive characteristics, there remain two important drawbacks to MAPI and related materials. First is the toxicity of lead, the inclusion of which in consumer electronics is undesirable due to the chance of extensive environmental release. Second, MAPI is unstable in moist air and rapidly degrades when held at operating temperatures, forming methylammonium iodide and $\mathrm{PbI}_{2}{ }^{12}$

The perovskite structure, with the general chemical formula $\mathrm{ABX}_{3}$, has very many well-studied examples among oxides and fluoride compounds $(\mathrm{X}=\mathrm{O}, \mathrm{F})$, and is synonymous in those fields with versatility of composition: typically in oxides and fluorides a very wide range of metal cations can be substituted onto the $\mathrm{A}$ and $\mathrm{B}$ sites, providing that simple geometrical conditions are met. ${ }^{13}$ This allows materials to be finely tuned by varying composition to elicit a wide range of properties from magnetism to ionic conductivity to catalysis.

Thus, to overcome the disadvantages of MAPI, it would initially seem that an approach of partially or completely substituting $\mathrm{A}, \mathrm{B}$, or $\mathrm{X}$ ions in the MAPI perovskite structure, may be successful. Attempts to replace $\mathrm{Pb}$ (II) on the $\mathrm{B}$ site have used the other divalent post-transition group 14 ions $\mathrm{Sn}(\mathrm{II})$ and $\mathrm{Ge}(\mathrm{II}){ }^{14}$ however, the stability of the $2+$ oxidation state decreases in the lighter group 14 elements, such that $\mathrm{Sn}$ and $\mathrm{Ge}$ favor the 4+ oxidation state, which cannot be accommodated in the halide perovskite structure. ${ }^{14}$ Thus, though removal of $\mathrm{Pb}$ is possible while maintaining the perovskite structure, doing so exacerbates the problem of instability. Substitutions on the A site have been similarly limited in success. While, on geometric grounds, various A-site

Received: December 2, 2015

Published: March 14, 2016 
cations have been proposed to form cubic lead iodide $\mathrm{ABX}_{3}$ arrays (hydroxylammonium, hydrazinium, azetidinium, imidazolium, and guanidinium), ${ }^{15}$ only methylammonium (MA) and formamidinium are currently known to do so. ${ }^{11,16}$ For instance, replacing the MA cations of the MAPI structure with either ethylammonium or ammonium results in a structural change from cubic perovskite to a $2 \mathrm{H}$ hexagonal perovskite with one-dimensional (1D) lead iodide chains, a significant loss of dimensionality leading to a wider band gap and inferior transport properties. ${ }^{17}$ Since only small A-site organic components are permissible within the $3 \mathrm{D}$ perovskite structure, optically or electronically active groups, such as conjugated $\pi$-systems, cannot be included. Lower-dimensional classes of organic haloplumbate compounds that can accommodate larger organic units are known. These consist of perovskite units separated by larger organic cations, such as $\mathrm{A}_{2} \mathrm{PbX}_{4}, \mathrm{~A}_{3} \mathrm{PbX}_{5}$, and $\mathrm{A}_{4} \mathrm{PbX}_{6}$ classes, which yield two-, one-, and zero-dimensional (OD) inorganic sublattices, respectively. ${ }^{18}$

Finally, substitution of iodide with lighter halides in the $\mathrm{X}$ site leads to an increase in the band gap (2.3 eV for $\left.\mathrm{MAPbBr}_{3}\right)$, hindering theoretical solar cell efficiency. ${ }^{4 a, 19}$

Hence, despite the promising foundation of the perovskite structure, which is highly tunable in oxides and fluorides, it has proved impossible to meet the challenges of overcoming the toxicity and instability of MAPI through a "materials design" approach of substituting the $\mathrm{A}, \mathrm{B}$, or $\mathrm{X}$ ions. ${ }^{20}$ Indeed, the wellestablished idea of tuning individually the inorganic and organic components of hybrid optoelectronic materials ${ }^{21}$ is virtually impossible within the cubic perovskite structure for the reasons mentioned. Instead, progress in MAPI devices has largely been made not in discovery of new compositions but rather in advancements in fundamental understanding of the material, ${ }^{22}$ device characterization, and manufacturing processes. ${ }^{20,23}$

Here we consider alternative inorganic-organic materials as photoactive agents for potential use in photovoltaic (PV) devices. As already stated, when the A site of hybrid perovskites is altered, a major drawback is that a reduction in inorganic dimensionality appears unavoidable, and this leads to a widening of the band gap and lowering of the conductivity. ${ }^{24}$ To counter this, we propose construction of materials with mixed organic and inorganic connectivity, where the organic component allows charge transport in one or more dimensions. We envisage that use of planar aromatic organic ligands that favor highly oriented $\pi$-stacking conformations with structuredirecting effects will produce conjugated pathways suitable for electron and hole transport. ${ }^{25}$ These structures would compensate for reduced inorganic dimensionality with increased organic connectivity, lifting the stringent requirements of the perovskite structure and opening a much larger compositional space for exploration and design of hybrid solar materials. $^{26}$ As a demonstration of this approach, here we report synthesis and characterization of novel $\mathrm{Bi}$ and $\mathrm{Pb}$ dipyrido iodide coordination complexes. We choose $\mathrm{Pb}(\mathrm{II})$ and $\mathrm{Bi}(\mathrm{III})$ compounds since these metals have lone pair $6 \mathrm{~s}^{2}$ configurations thought necessary to aid charge carrier mobility. ${ }^{20} \mathrm{~Pb}(\mathrm{II})$ and $\mathrm{Bi}(\mathrm{III})$ are also more resistant to oxidation compared to their lighter analogues $\mathrm{Sn}(\mathrm{II})$ and $\mathrm{Sb}(\mathrm{III})$. By studying compounds of two related conjugated ligands, we show the dimensionality of the inorganic portion can be controlled, and furthermore, the optical and electronic properties are promising for photovoltaic application. Specifically, we combine lead and bismuth iodide with dipyrido[3,2$\left.a: 2^{\prime}, 3^{\prime}-c\right]$ phenazine (dppz) and benzo $[i]$ dipyrido $\left[3,2-a: 2^{\prime}, 3^{\prime}-\right.$ c]phenazine (dppn) (see Figure S1 in Supporting Information). We have characterized the structural configurations, electronic band positions, theoretical partial charges, and band structures and show they have potential as a class of highly tunable organic-inorganic photoactive materials with long-lived charge separation lifetimes and chemical stability.

\section{RESULTS AND DISCUSSION}

Synthesis of the lead and bismuth iodide dppz and dppn complexes was achieved through solution-phase methods. Both organic ligands dppz and dppn can be synthesized through nonair-sensitive, catalyst-free processes using ethanolic solutions from easily available starting materials. Single-crystal synthesis of the $\mathrm{PbI}_{2}$ and $\mathrm{BiI}_{3} \mathrm{dppz}$ and dppn complexes was achieved through solvent layering by use of either $N$-methyl-2pyrrolidone (NMP) or dimethylformamide (DMF) to dissolve the reagents and a layer of methanol to induce crystallization.

Structural Characterization. Lead(II) iodide heterocyclic compounds $\left[\mathrm{Pb}(\mathrm{dppz}) \mathrm{I}_{2}\right]_{n}$, also referred to as $\mathrm{PbI}_{2}-\mathrm{dppz}(\mathbf{1})$, and $\left[\mathrm{Pb}(\mathrm{dppn})_{2} \mathrm{I}_{2}\right]$ or $\mathrm{PbI}_{2}$-dppn (2), and bismuth(III) iodide heterocyclic compounds $\left[\mathrm{Bi}(\mathrm{dppz}) \mathrm{I}_{3}\right]_{2}$ or $\mathrm{BiI}_{3}-\mathrm{dppz}(3)$ and $\left[\mathrm{Bi}(\mathrm{dppn}) \mathrm{I}_{3} \cdot \mathrm{NMP}\right]$ or $\mathrm{BiI}_{3}$-dppn (4), were structurally determined by X-ray crystallography (Figure 1; Table S1 in Supporting Information). Compound $\mathbf{1}$ crystallized in the monoclinic space group $I 2 / a$ (Figure 1a,e; Figure S2). The asymmetric unit of 1 consists of a lead diiodide unit coordinated to one dppz ligand through two nitrogen atoms. A one-dimensional chain is formed from $\mathrm{Pb}-\mathrm{I}$ bridges between $\left[\mathrm{Pb}(\mathrm{dppz}) \mathrm{I}_{2}\right]$ monomeric units, each lead center is coordinated

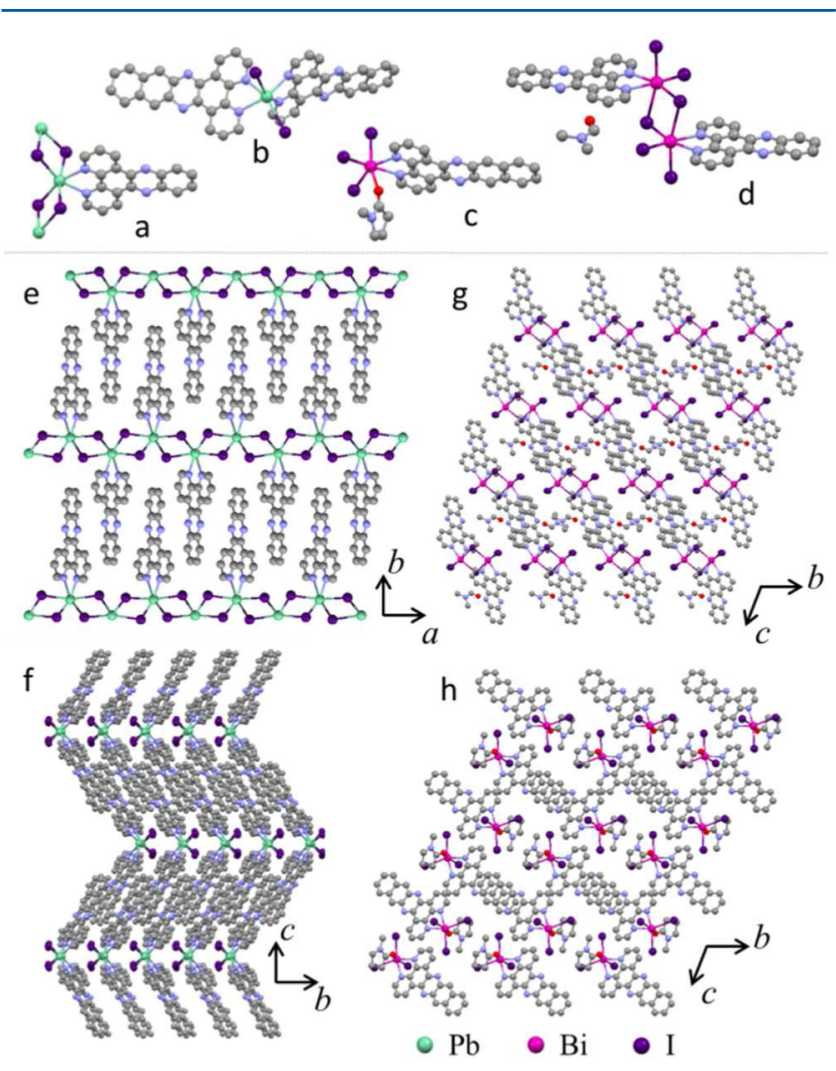

Figure 1. Molecular structures of (a) $\mathrm{PbI}_{2}$-dppz (1), (b) $\mathrm{PbI}_{2}$-dppn (2), (c) $\mathrm{BiI}_{3}$-dppn (4), and (d) $\mathrm{BiI}_{3}$-dppz (3). Packed extended structures are shown for (e) $\mathrm{PbI}_{2}$-dppz viewed to show the $\mathrm{Pb}-\mathrm{I} 1 \mathrm{D}$ linear chains and overlapping dppz ligands, (f) $\mathrm{PbI}_{2}$-dppn, (g) $\mathrm{BiI}_{3}-$ $\mathrm{dppz}$, and $(\mathrm{h}) \mathrm{BiI}_{3}$-dppn viewed showing the eclipsed organic moieties. 
by four iodine atoms and two nitrogen atoms from the dppz ligand, resulting in a distorted octahedral geometry.

The infinite chain along the $c$-axis of alternating lead and iodine atoms is very similar to the previously reported compounds $\left[\mathrm{Pb}\left(2,2^{\prime}\right.\right.$-bipy $\left.) \mathrm{I}_{2}\right]$ and $\left[\mathrm{Pb}(1,10\right.$-phen $\left.) \mathrm{I}_{2}\right]$, with dppz ligands lying on alternate sides of each chain; bond lengths about the metal center are similar to those reported previously. As in $\left[\mathrm{Pb}\left(2,2^{\prime}\right.\right.$-bipy $\left.) \mathrm{I}_{2}\right]$ and $\left[\mathrm{Pb}(1,10\right.$-phen $\left.) \mathrm{I}_{2}\right], \mathbf{1}$ is consistent with Brown's model of two strong $\mathrm{Pb}-\mathrm{N}$ bonds [2.519(6) and 2.574(7) $\AA]$ and two intermediate [3.215(7) and $3.192(7) \AA]$ and two weak $[3.320(7) \AA] \mathrm{Pb}-\mathrm{I}$ bonds. ${ }^{28}$ The $\mathrm{I}(1)-\mathrm{Pb}(1)-\mathrm{I}(2)$ bond angle deviates from the expected $180^{\circ}$ considerably $\left[168.13(9)^{\circ}\right]$ and may be attributed to the tendency for the $\mathrm{Pb}$ (II) 6 s electron pair to hybridize with the $6 \mathrm{p}$ orbitals such that it occupies a position in the coordination sphere, leading to hemidirected coordination. ${ }^{29}$ Furthermore, the $\mathrm{N}-\mathrm{M}-\mathrm{I}$ bond angles also deviate from the expected $90^{\circ}$ (mean value $83.86^{\circ}$ ); this is likely due to the rigidity of the dppz ligand as it stacks up in the $1 \mathrm{D}$ array. Static disorder is observed throughout the structure, with the ligand and iodine atoms fractionally displaced giving two parts, both with $50 \%$ occupancy; see Experimental Section for further discussion.

Compound $\mathbf{2}$ is mononuclear, crystallizes in the monoclinic space group $C 2 / c$, and has a distorted octahedral geometry (Figure 1b,f; Figure S3). The crystal structure of $\mathbf{2}$ has been reported previously. ${ }^{30}$ The lead atom is surrounded by four nitrogen atoms, forming strong bonds with each of the two dppn ligands $(\mathrm{Pb}-\mathrm{N}$ average distance $2.59(4) \AA)$ and two iodine atoms $(\mathrm{Pb}-\mathrm{I}$ average distance $3.22(1) \AA)$, which is indicative of an intermediate bonding interaction. The bite angle of the ligand $\left[\mathrm{N}(1)-\mathrm{Pb}(1)-\mathrm{N}(2), 62.94(17)^{\circ} ; \mathrm{N}(3)-\right.$ $\left.\mathrm{Pb}(1)-\mathrm{N}(4), 63.33(17)^{\circ}\right]$ in 2 is smaller than in comparable complexes, ${ }^{27}$ which is also observed in the structurally analogous $\left[\mathrm{Pb}(\mathrm{dppz})_{2} \mathrm{I}_{2}\right]^{30}$ and leads to a range in cis angles $\left[62.94(17)^{\circ}-107.47(12)^{\circ}\right]$ differing from the expected $90^{\circ}$. This results in mononuclear molecular formation organized through $\pi$-stacking of the highly conjugated aromatic dppn ligand forming staggered nonbonding sheets in the ac-plane as shown in Figure 1f, which is viewed down the $c$-axis through the eclipsed overlapping organic units.

Compound 3 crystallized in the triclinic space group $P \overline{1}$ and consists of a dimeric structure bridged by two iodine atoms (Figure 1d,g; Figure S4). ${ }^{31}$ The centrosymmetric fourmembered $\mathrm{Bi}_{2} \mathrm{I}_{2}$ ring is planar, with the remainder of the coordination sphere of the bismuth atoms being filled with two terminal iodine atoms and the two nitrogen atoms of the dppz ligand.

The $\mathrm{Bi}-\mathrm{N}$ bonds are indicative of strong bonds (mean value $2.501 \AA$ ) and the difference between the bridging $\mathrm{Bi}-\mathrm{I}$

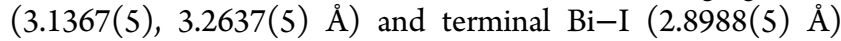
bond lengths is obvious. Each bismuth center in 3 adopts a distorted octahedral six-coordinate geometry (see bond angles in Table S2), and can be assigned in part to the smaller bite angle of the ligand $\left[\mathrm{N}(1)-\mathrm{Pb}(1)-\mathrm{N}(2) 66.53(17)^{\circ}\right]$.

Compound 4 is made up of a $\mathrm{BiI}_{3}$ unit coordinated to a dppn ligand via nitrogen atoms in two positions, completing the octahedral sphere of this mononuclear compound is a molecule of solvent, NMP (Figure 1c,h; Figure S5). Compound 4 crystallized in the triclinic space group $P \overline{1}$ with typical $\mathrm{Bi}-\mathrm{N}$ bond lengths observed (average 2.54(4) $\AA$ ), and in the absence of dimerization or formation of a $1 \mathrm{D}$ chain, as in $\mathbf{1}$ and 3 , there is an average $\mathrm{Bi}-\mathrm{I}$ bond length of 2.98(4) Å. Despite the lack of steric constraints seen in 1-3, a large deviation from the expected octahedral geometry is still observed (Table S2). This is likely, in part, due to the small bite angle of the dppn ligand $\left[64.95(12)^{\circ}\right]$, which is slightly larger than the bite angle of the same ligand in $2\left[62.94(17)^{\circ}\right]$; however, when the change in ionic radius when moving from lead to bismuth is considered, this is as expected.

Polycrystalline samples of $1-4$ were measured by powder Xray diffraction (PXRD) (Figure $2 \mathrm{a}, \mathrm{b}$ ). The measured data are
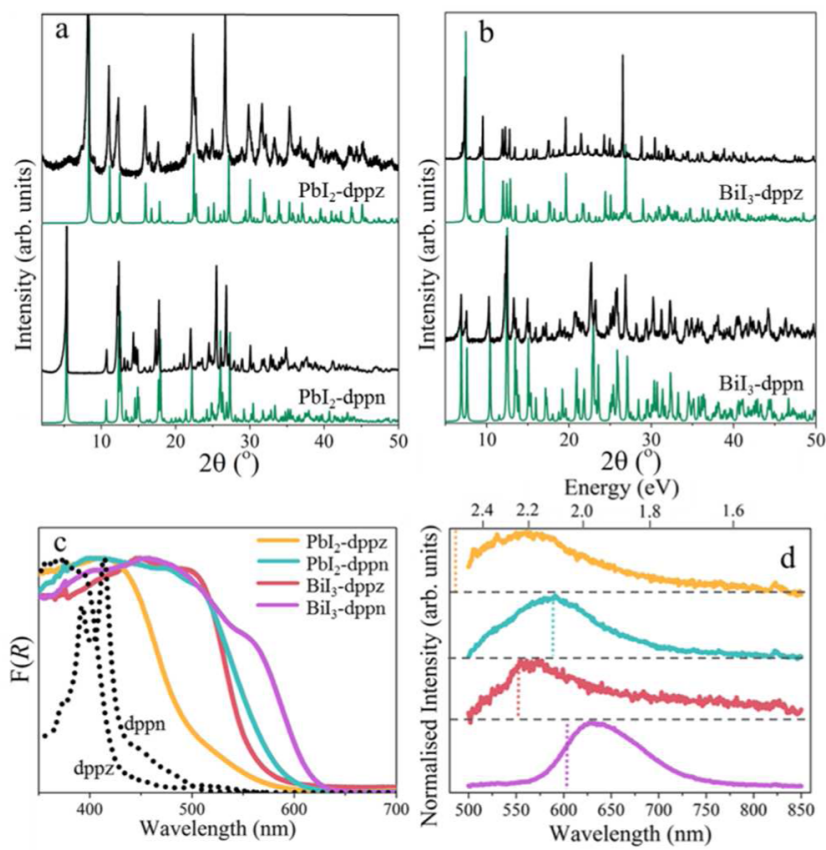

Figure 2. Measured (black) and simulated (green) PXRD patterns for (a) $\mathrm{PbI}_{2}$-dppz and $\mathrm{PbI}_{2}$-dppn and (b) $\mathrm{BiI}_{3}$-dppz and $\mathrm{BiI}_{3}$-dppn. (c) $\mathrm{UV}-$ vis absorbance spectra of dppz and dppn ligands and $\mathrm{Pb}$ and $\mathrm{Bi}$ dipyrido complexes. (d) Photoluminescence (PL) spectra of $\mathrm{Pb}$ and $\mathrm{Bi}$ dipyrido complexes. Band gaps derived from Tauc plots are highlighted with vertical lines.

in good agreement with the simulated patterns derived from single-crystal structures. After 2 months exposure to air, repeat PXRD measurements (Figure S6) showed the materials to be robust with no degradation observed. Conversely, MAPI decomposes, turning yellow (with formation of $\mathrm{PbI}_{2}$ ), within $24 \mathrm{~h}$ of exposure to air.

Optical and Electronic Characterization. Optical spectra of polycrystalline samples 1-4 and of the ligands, dppn and $\mathrm{dppz}$, in the solid state were measured in diffuse reflection mode by UV-vis spectrophotometer (Figure 2c). The asrecorded reflectance values were transformed with the Kubelka-Munk function, $F(R)$, to give spectral intensity proportional to the absorbance.

The unbound ligands dppn and dppz show principal absorption features at wavelengths below $450 \mathrm{~nm}$ (Figure 2c). Compounds 1-4 all show optical absorption at significantly longer wavelengths than the unbound organic ligands. The absorption spectra of $\mathbf{1 - 4}$ all contain an absorption edge, and from this feature the optical band gaps for the complexes were obtained by constructing Tauc plots of $[F(R) E]^{2}$ (Figure S7). ${ }^{32}$ For $\mathbf{1}$ and 2, band gaps were determined as 2.52 and $2.13 \mathrm{eV}$, respectively, and for 3 and 4 they were 2.24 and $2.05 \mathrm{eV}$, respectively. For comparison, the binary halides $\mathrm{PbI}_{2}$ and $\mathrm{BiI}_{3}$ have band gaps at room 
temperature of $2.35 \mathrm{eV}(\lambda=527 \mathrm{~nm})^{33}$ and $1.96 \mathrm{eV}(\lambda=632$ $\mathrm{nm}) .34$

Figure $2 \mathrm{~d}$ shows the normalized photoluminescence (PL) spectra for the novel hybrid materials. The PL of the free ligands is shown in Figure S8 (Supporting Information). $\mathrm{BiI}_{3}$ dppn has a PL maximum at $630 \mathrm{~nm}$, at slightly lower energy than the band gap (indicated by a vertical line in Figure $2 \mathrm{~d}$ ). $\mathrm{PbI}_{2}$-dppn in contrast shows a $\mathrm{PL}$ emission peak with a maximum almost exactly coincident with the band gap energy. $\mathrm{BiI}_{3}$-dppz showed very weak photoluminescence, with peak emission at $560 \mathrm{~nm}$, again at slightly lower energy than the band gap. The close coincidence between the PL maximum and band gap energy in these three compounds suggests that the defect concentration in the band gap is relatively low. $\mathrm{PbI}_{2}$-dppz showed a much larger difference between band gap and PL emission maximum. This may be related to the tailing seen in the $\mathrm{PbI}_{2}$-dppz optical absorption spectrum (Figure $2 \mathrm{c}$ ) below the absorption edge, indicative of defect states within the band gap. It is notable that the solution-processed materials reported here are both highly crystalline (PXRD analysis, Figure 2a,b and Figure S6) and PL-active. Conversely, Kanatzidis and coworkers $^{11 a}$ found that hybrid perovskite materials synthesized by similar solution-processing methods and of high crystallinity are PL-inactive. The fact that $\mathbf{1 - 4}$ are concurrently crystalline and PL-active may be explained by the PL activity of the ligands with the greater extinction coefficient of the dppn ligand giving rise to more active complexes.

The optical band gap of PV absorber materials is critical to their function. In the hybrid PV field to date, it has been noted that band gaps tend to decrease with increasing dimensionality of the inorganic sublattice and with increasing mass of the halide anion. ${ }^{35}$ For example, in the series $\mathrm{RNH}_{3} \mathrm{PbI}_{3}$, when $\mathrm{R}=$ methyl (MAPI), the structure has 3D connectivity of the inorganic sublattice and a band gap of $1.5 \mathrm{eV}$. Increasing the size of the A-site cation results in lower inorganic dimensionality: for example, when $\mathrm{R}$ = ethyl or propyl, both adopt the hexagonal perovskite structure with $1 \mathrm{D}$ connectivity of the inorganic sublattice and show considerably larger band gaps of 2.20 and $2.40 \mathrm{eV}$, respectively. ${ }^{17 \mathrm{a}, 24}$

In the $\mathrm{Pb}(\mathrm{II})$ and $\mathrm{Bi}(\mathrm{III})$ systems studied here, the larger conjugated organic ligand (dppn) induces a smaller band gap, contrary to the trend seen for the simple aliphatic organic ions mentioned above. This is the case even in the two $\mathrm{Pb}$ (II) complexes that show different inorganic dimensionality: the smaller dppz ligand induces $1 D$ lead iodide chains, whereas the larger dppn ligand results in dimeric, OD inorganic clusters. Thus the relationship observed in $\mathrm{RNH}_{3} \mathrm{PbI}_{3}$ compounds, that greater inorganic dimensionality results in a smaller band gap, is not observed in this case, which indicates that for these systems band gaps can be tuned independently of inorganic connectivity, or that lower inorganic dimensionality can be compensated for by increased organic dimensionality.

In the hybrid perovskites, shorter average $\mathrm{M}-\mathrm{I}$ bond lengths and reduced octahedral distortion corresponds to smaller band gap materials. ${ }^{36}$ This trend can also be observed here, with $\mathrm{BiI}_{3}-$ dppn having the lowest band gap of $2.05 \mathrm{eV}$ and lowest average $\mathrm{M}-\mathrm{I}$ bond length; by contrast, $\mathrm{PbI}_{2}$-dppz has the largest band gap of $2.52 \mathrm{eV}$ and longest average $\mathrm{M}-\mathrm{I}$ bond length (Table S2). Conversely, the $\mathrm{M}-\mathrm{N}$ bond lengths cannot be correlated to band gap variances. While octahedral distortion has been observed for wider band gap perovskite materials, here the opposite is apparent. Distortion from the ideal bond angle of $180^{\circ}$ in octahedral geometry is much less for $\mathrm{PbI}_{2}$-dppz (I-
$\mathrm{Pb}-\mathrm{I}$ angle $168.13^{\circ}$ ) than for $\mathrm{PbI}_{2}$-dppn ( $\mathrm{I}-\mathrm{Pb}-\mathrm{N}$ angle $\left.152.37(13)^{\circ}\right)$, with the former having a larger band gap (2.52 vs $2.13 \mathrm{eV}$ ). Octahedral distortion is also less for $\mathrm{BiI}_{2}$-dppz (I$\mathrm{Bi}-\mathrm{I}$ angle $166.48^{\circ} ; E_{\mathrm{g}}=2.24 \mathrm{eV}$ ) than for $\mathrm{BiI}_{2}$-dppn (I-Bi-O angle $\left.162.43(9)^{\circ} ; E_{\mathrm{g}}=2.05 \mathrm{eV}\right)$. That the organic components are electronically active in these materials, while the formamidinium and methylammonium from previous studies are not, goes some way to explain these differences. ${ }^{11 a}$

In summary, 1-4 show optical spectra characteristic of semiconductors with band gaps in the range $2.05-2.52 \mathrm{eV}$, reasonably close to that required for efficient photovoltaic absorbers. ${ }^{37}$ The trend in band gap within this limited range of compounds seems to indicate that both the size of the organic conjugated system and the identity of the metal play important roles in determining the optical properties. These results support the hypothesis that not only through modification of the inorganic component but also by varying the organic ligand can the optical properties of these materials be tuned, leading to a rich parameter space for further exploration.

Band energy positions (Figure 3) for the materials were determined by depositing 1-4 as thin films by spray deposition

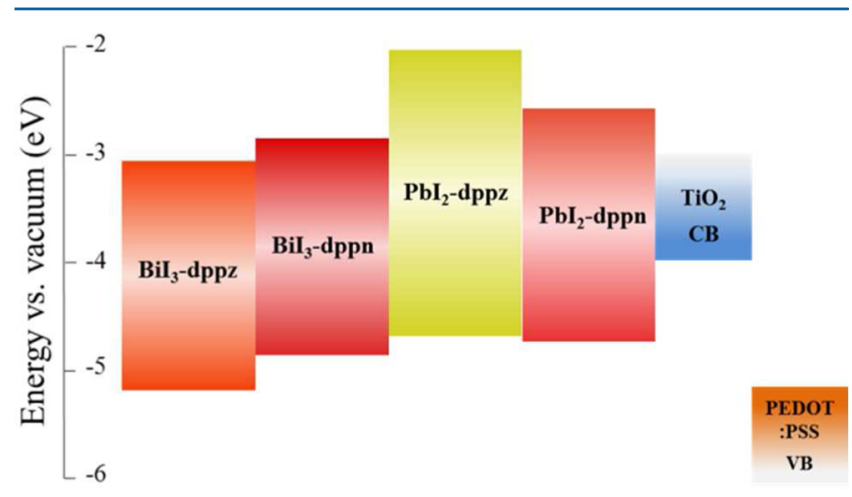

Figure 3. Band alignment for $\mathrm{Pb}$ and $\mathrm{Bi}$ dipyrido complexes. The positions of typical functional layer materials used in photovoltaic devices [e.g., conduction band of typical ETL $\mathrm{TiO}_{2}(-4.0 \mathrm{eV})^{6}$ and valence band level of common HTL PEDOT:PSS $(5.20 \mathrm{eV})]$ are shown for comparison.

of the respective metal halide and organic ligand in DMF or NMP solution onto heated substrates, and the films were analyzed by XPS (Figure S9 and Table S3). The energy of the valence band maximum relative to the Fermi level was determined via linear extrapolation of the valence band onset to the spectral background. Work functions for the materials were obtained by applying a sample bias of $30 \mathrm{~V}$ and measuring the low kinetic energy threshold of the XPS spectrum. ${ }^{38}$ Determination of the energy levels allows prediction of suitable junction fabrications using typical electron transport (ETL) and hole transport layers (HTL); for example, the $\mathrm{BiI}_{3}$-dppz energy levels suggest a $\mathrm{TiO}_{2} / \mathrm{BiI}_{3}$-dppz/PEDOT:PSS junction would be well-matched for charge separation (Figure 3). ${ }^{39}$ The materials are easily solution-processed and films can be readily fabricated as shown in Figure S10.

Theoretical Analysis. Each structure was optimized by use of the PBEsol functional initially, and then the hybrid functional HSE06 was applied in each case to obtain an accurate electronic band structure. A comparison of relaxed theoretical structures and experimental results is presented in Table S4, demonstrating the accuracy of the PBEsol functional at describing these structures, with differences attributable to thermal effects. Band 
structures for each of the four compounds are also depicted (Figure S11). The effect of spin-orbit coupling on the electronic structures was found to be negligible, as shown by the PBEsol and PBEsol+SOC band structures (Figure S12S15). As such, we expect the HSE06 band gap values to provide a reasonable estimate of the band gap magnitude, without the additional spin-orbit perturbation usually required in hybrid lead halide perovskites. ${ }^{40}$ In all cases, the compounds were found to be medium to wide band gap semiconductors, with both valence and conduction bands showing negligible dispersion.

Of particular interest are the characters of the valence and conduction band edges. Figures 4 and 5 show the partial

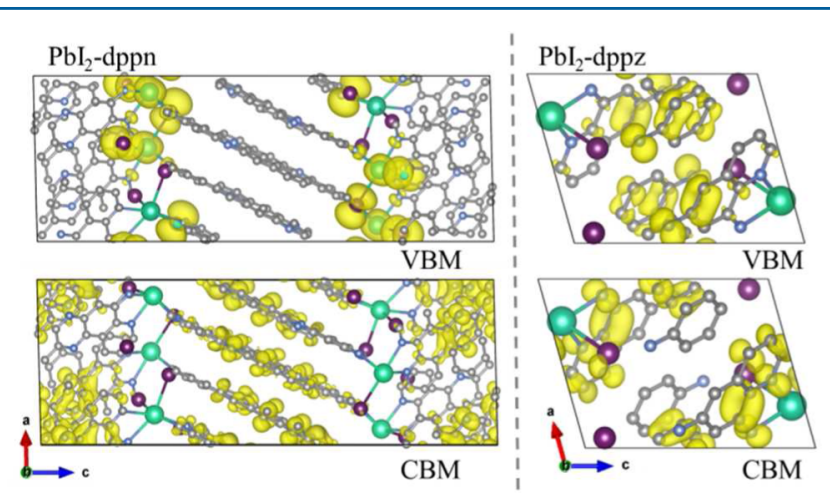

Figure 4. Partial charges of VBM and CBM for lead iodide complexes by use of HSE06 functional.

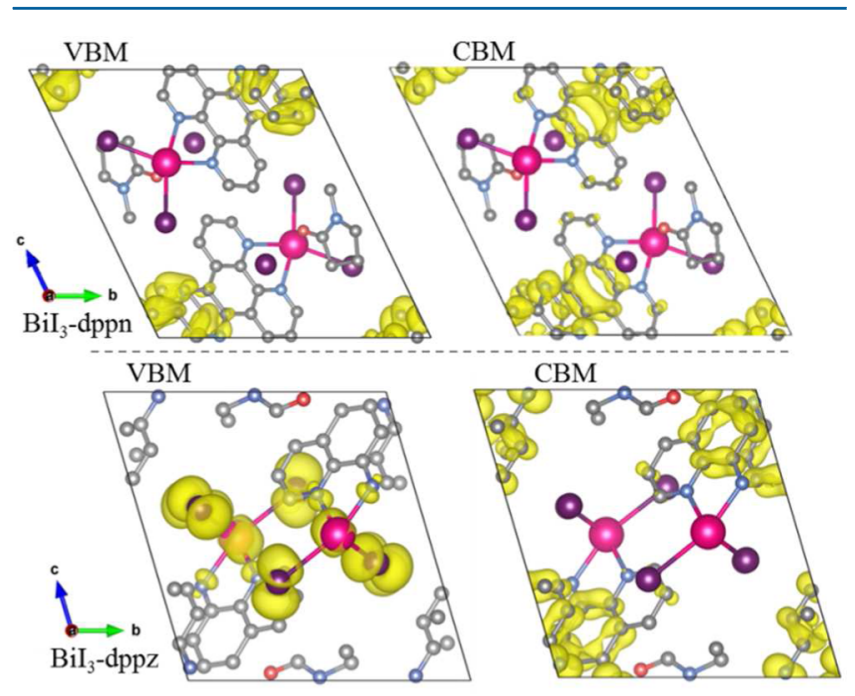

Figure 5. Partial charges of VBM and CBM for bismuth iodide complexes by use of HSE06 functional.

charges for valence band maximum (VBM) and conduction band minimum $(\mathrm{CBM})$ energy levels. In $\mathrm{BiI}_{3}-\mathrm{dppz}$ and $\mathrm{PbI}_{2}-$ dppn, the valence band lies on the inorganic portion of the complex, composed of lead or bismuth s states with iodine $p$ states (Figures S12 and S15). Alternatively the conduction band is localized on the organic ligand, constituting carbon $s$ and $\mathrm{p}$, nitrogen $\mathrm{p}$, and hydrogen states. This gives rise to exciton charge separation across the inorganic/organic components and the potential for long-lived charge-separated states derived from an active organic cation species, ${ }^{41}$ which may lead to the reduction of recombination losses. ${ }^{42}$ In $\mathrm{BiI}_{3}$ dppn and $\mathrm{PbI}_{2}$-dppz, both conduction and valence bands are localized on the organic ligand, therefore not facilitating exciton separation; rationalizing these structural and electronic differences may therefore be a fruitful area of study.

The calculated carrier effective masses (Table S5) are almost an order of magnitude higher than those of MAPI, ${ }^{43}$ indicating significantly poorer charge transport of both holes and electrons. The key comparison to be made between experimental and theoretical results is in the band gap trend; the indirect and direct band gaps of each compound are listed in Table S6. The dppn systems have significantly smaller band gaps than the dppz compounds, in agreement with experimentally observed trends. Underestimation of the calculated band gaps compared to experiment, when the HSE06 functional is used, has previously been observed in other semiconductors. ${ }^{44}$

\section{CONCLUSIONS}

Four post-transition metal iodide dipyrido coordination complexes have been synthesized and structurally characterized. These materials demonstrate promising tunability of their optical, structural, and electronic properties and show promise for potential applications as PV absorbers. As such, they represent a possible alternative to the perovskite structure, which offers very little compositional flexibility.

\section{EXPERIMENTAL SECTION}

1,10-Phenanthroline, o-phenylenediamine, 2,3-diaminonaphthalene, lead(II) nitrate, potassium iodide, and bismuth(III) iodide were all purchased from Sigma-Aldrich and used without further purification.

Caution! The lead compounds utilized are toxic, and measures must be taken to avoid exposure of workers. An especially hazardous step is the spray coating of thin films, as without proper controls it may result in inhalation of lead-containing chemicals and toxic solvents.

Reagent Synthesis. Synthesis of 1,10-Phenanthroline-5,6-dione. Potassium bromide (1.999 g, $16.80 \mathrm{mmol})$ and 1,10-phenanthroline $(2.220 \mathrm{~g}, 11.20 \mathrm{mmol})$ were added to an ice-cold solution of sulfuric acid $(98 \%, 20 \mathrm{~mL})$ and nitric acid $(68 \%, 10 \mathrm{~mL})$. The reaction was heated at reflux for $5 \mathrm{~h}$ before the warm solution was poured over ice and neutralized with sodium hydroxide. 1,10-Phenanthroline-5,6-dione was extracted with chloroform, anhydrous magnesium sulfate was added, and the solution was filtered and then dried in vacuo. ${ }^{1} \mathrm{H}$ NMR $\left(600 \mathrm{MHz}, \mathrm{CDCl}_{3}\right) 9.14(\mathrm{dd}, J=4.7,1.7 \mathrm{~Hz}, 2 \mathrm{H}), 8.52(\mathrm{dd}, J=7.9$, $1.5 \mathrm{~Hz}, 2 \mathrm{H}), 7.60(\mathrm{~m}, 2 \mathrm{H}) \mathrm{ppm}$.

Synthesis of Dppz. Ethanolic solutions of 1,10-phenanthroline-5,6dione $(0.500 \mathrm{~g}, 2.379 \mathrm{mmol})$ and $o$-phenylenediamine $(0.386 \mathrm{~g}, 3.568$ $\mathrm{mmol}$ ) were combined and refluxed for $6 \mathrm{~h}$ before being cooled to obtain a solid. The solid was filtered off and recrystallized from ethanol. Dppz: ${ }^{1} \mathrm{H}$ NMR $\left(600 \mathrm{MHz}, \mathrm{CDCl}_{3}\right): \delta_{\mathrm{H}} 9.71(\mathrm{dd}, J=8.0,1.5$ $\mathrm{Hz}, 2 \mathrm{H}), 9.32(\mathrm{~d}, J=3.0 \mathrm{~Hz} 2 \mathrm{H}), 8.39$ (dd, $J=6.5,3.4 \mathrm{~Hz}, 2 \mathrm{H}), 7.96$ (dd, $J=6.5,3.3 \mathrm{~Hz}, 2 \mathrm{H}), 7.85$ (dd, $J=8.0,4.5 \mathrm{~Hz}, 2 \mathrm{H}$ ).

Synthesis of Dppn. Ethanolic solutions of 1,10-phenanthroline-5,6dione $(0.500 \mathrm{~g}, 2.379 \mathrm{mmol})$ and 2,3-diaminonaphthalene $(0.377 \mathrm{~g}$, $2.386 \mathrm{mmol}$ ) were combined and refluxed for $5 \mathrm{~h}$ before being cooled to obtain a solid. The solid was filtered off and recrystallized from ethanol. Dppn: ${ }^{1} \mathrm{H}$ NMR $\left(600 \mathrm{MHz}, \mathrm{CDCl}_{3}\right): \delta_{\mathrm{H}} 9.68(\mathrm{dd}, J=8.1,1.6$ $\mathrm{Hz}, 2 \mathrm{H}), 9.30(\mathrm{~d}, J=2.9 \mathrm{~Hz}, 2 \mathrm{H}), 8.97(\mathrm{~s}, 2 \mathrm{H}), 8.22(\mathrm{dd}, J=6.4,3.2$ $\mathrm{Hz}, 2 \mathrm{H}), 7.83$ (dd, $J=8.0,4.4 \mathrm{~Hz}, 2 \mathrm{H}), 7.65$ (dd, $J=6.6,3.0 \mathrm{~Hz}, 2 \mathrm{H})$.

Synthesis of Lead(II) lodide. Separate $50 \mathrm{~mL}$ aqueous solutions of lead(II) nitrate $(14.240 \mathrm{~g}, 0.043 \mathrm{~mol})$ and potassium iodide (14.289 g, $0.086 \mathrm{~mol}$ ) were prepared. Upon mixing together, lead(II) iodide formed immediately as a yellow precipitate, which was separated via filtration and washed thoroughly with deionized water.

Polycrystalline Sample Synthesis. Polycrystalline forms of the materials were synthesized through solvent evaporation: DMF was used for the dppz complexes, while NMP was required for preparation of the larger dppn-containing species. 
$\mathrm{Pbl}_{2}$-dppz (1). Dppz (0.050 g, $\left.0.177 \mathrm{mmol}\right)$ was dissolved in a minimum amount of methanol by heating. In addition, concentrated methanolic solutions of sodium iodide $(0.053 \mathrm{~g}, 0.355 \mathrm{mmol})$ and lead(II) acetate trihydrate $(0.132 \mathrm{~g}, 0.177 \mathrm{mmol})$ were prepared. Upon addition of the three solutions together, a yellow precipitate was formed, which was separated by filtration.

$\mathrm{Pbl}_{2}$-dppn (2). Dppn (0.050 g, $\left.0.150 \mathrm{mmol}\right)$ and lead(II) iodide $(0.069 \mathrm{~g}, 0.150 \mathrm{mmol})$ were separately dissolved in minimum amounts of NMP. The solutions were combined and left under continuous air flow for several days before being dried in air at $170{ }^{\circ} \mathrm{C}$.

$\mathrm{Bil}_{3}$-dppz (3). Dppz (0.050 g, $\left.0.177 \mathrm{mmol}\right)$ was dissolved in anhydrous DMF ( $1 \mathrm{~mL}$ ) by heating and then added cold to a solution of bismuth(III) iodide (0.104 g, $0.177 \mathrm{mmol})$ in DMF $(1 \mathrm{~mL})$. The resultant orange/brown solution was heated under continuous air flow at $125{ }^{\circ} \mathrm{C}$ until a dry solid was obtained.

$\mathrm{Bil}_{3}$-dppn (4). Dppn (0.050 g, $\left.0.150 \mathrm{mmol}\right)$ and bismuth(III) iodide $(0.089 \mathrm{~g}, 0.150 \mathrm{mmol})$ were separately dissolved in minimum amounts of NMP and prepared as for 2 .

Single-Crystal Synthesis. Single crystals were synthesized through solvent layering, with DMF used for $\mathbf{1}$ and $\mathbf{3}$ and NMP for 2 and 4, as exemplified below.

Dppz (0.050 g, $0.177 \mathrm{mmol})$ was dissolved with heating in anhydrous DMF $(1 \mathrm{~mL})$ and then added cold to a solution of bismuth(III) iodide (0.104 g, $0.177 \mathrm{mmol})$ in DMF $(1 \mathrm{~mL})$. The resultant orange/brown solution was layered under methanol in an NMR tube. After several days, orange crystals had grown and were used for structure determination.

Sample Characterization. Powder X-ray diffraction (PXRD) data were collected on a Stoe StadiP diffractometer using $\mathrm{Cu} \mathrm{K} \alpha{ }_{1}$ radiation, $\lambda=1.54056 \AA$. Capillaries $(0.5 \mathrm{~mm})$ were filled with powdered samples and data were collected over the $2 \theta$ range $2-60^{\circ}$ in steps of $0.5^{\circ}$ at $10 \mathrm{~s} / \mathrm{step}$.

Single-crystal X-ray diffraction data sets of 1-4 were collected on a SuperNova (dual source) Atlas diffractometer with $\mathrm{Cu} \mathrm{K} \alpha$ radiation $(\lambda$ $=1.54184 \AA$ ). Single crystals of 1-4 were mounted on Hampton Research $20 \mu \mathrm{m}$ nylon loops $(\Phi \approx 0.3 \mathrm{~mm}$ ) and kept at $150 \mathrm{~K}$ during data collection with the exception of $\mathbf{1}$, which was collected in addition at $100 \mathrm{~K}$. A summary of crystal data, data collection, and refinement for crystallographically characterized compounds is given in Table S1. By use of Olex2, ${ }^{45}$ structures were solved for $\mathbf{1}$ and 3 with the ShelXT ${ }^{46}$ structure solution program using Direct Methods and refined with the ShelXL ${ }^{47}$ refinement package using least-squares minimization. Also by use of Olex $2{ }^{45}$ structures for $\mathbf{2}$ and $\mathbf{4}$ were solved with the Superflip ${ }^{48}$ structure solution program using charge flipping and refined with the ShelXL ${ }^{47}$ refinement package using leastsquares minimization.

Data for 1 were initially collected at $150 \mathrm{~K}$, but due to suspected static disorder, the collection was repeated at $100 \mathrm{~K}$, which confirmed static and not dynamic disorder. In $\mathbf{1}$, the dppz ligand (point symmetry $2 / m$ ) does not lie with the 2-fold axis of the molecule along the 2 -fold axis of the space group. The disorder in the structure can be modeled with the 2-fold axis of the ligand skewed away from the crystallographic 2-fold axis, resulting in two positions for the ligand with 50\% occupancy. As a consequence of the disorder, a thermal constraint (EADP) was placed on pairs of atoms (e.g., N1 with N2, C1 with $\mathrm{C} 10$, C5 with C6 etc.) throughout the ligand, with isotropic displacement parameters deemed to give the best fit to the data.

While the disorder in $\mathbf{1}$ is observed with respect to the ligand, use of the dppn ligand in $\mathbf{2}$ with its larger conjugated $\pi$ system and stronger $\pi-\pi$ stacking interaction between ligands results in the disorder being manifest in the inorganic $\mathrm{PbI}_{2}$ component (Figure 1f). This leads to two different conformations about each lead cation with a refined occupancy ratio $4: 1$.

Following the synthesis of 3 , single-crystal data were collected at $150 \mathrm{~K}$. This structure has been recently published ${ }^{31}$ with the data published collected at room temperature with a final $R 1=0.0834$ and wR2 $=0.1947$ for 2749 observed reflections with $I>2 \sigma(I)$. Due to the significant difference in cell parameters and anisotropic displacement parameters, the data collected at $150 \mathrm{~K}$ are included here for comparison $(R 1=0.0342$, $\mathrm{w} R 2=0.0834$ for 4789 observed reflections with $I>2 \sigma(I)]$ and have been submitted to the Cambridge Structural Database.

UV-vis data was recorded on a Lambda 950 spectrophotometer equipped with an integrating sphere at ambient temperature. Powders were fixed to carbon tape and run in diffuse reflectance mode with a data collection step of $1 \mathrm{~nm}$. Photoluminescence spectroscopy was recorded on a Horiba FluoroMax 4 with a $150 \mathrm{~W}$ xenon lamp source and excitation radiation wavelength of $450 \mathrm{~nm}$. The powder samples were ground and sandwiched between float glass microscope slides, a glass slide background was removed, and the data were normalized.

Nuclear magnetic resonance was recorded on a Bruker Axis 600 $\mathrm{MHz}$. XPS and work function measurements were carried out on a Thermo Scientific $\mathrm{Al}-\mathrm{K} \alpha$.

Theoretical Methods. All calculations were performed via density functional theory (DFT) through the Vienna ab initio simulation package (VASP). ${ }^{49}$ Within VASP, the projector-augmented wave (PAW) method was used to describe interactions between the core and valence electrons. ${ }^{50}$ The two functionals used in the calculations were PBEsol, ${ }^{51}$ which is the Perdew-Burke-Ernzerhof $(\mathrm{PBE})^{52}$ generalized gradient approximation (GGA) functional adapted for solids, and HSE06, ${ }^{53}$ a hybrid functional that includes $25 \%$ screened Hartree-Fock exchange with correlation and $75 \%$ exchange from PBE, with a screening parameter of $\omega=0.11 \mathrm{bohr}^{-1}$. PBEsol has been successful at describing the structure of hybrid lead halides, ${ }^{22 a, 54,55}$ so it was used here for structure optimization, while HSE06 has been shown to accurately reproduce experimental band gaps for semiconductors. ${ }^{56,57}$ A cutoff energy of $400 \mathrm{eV}$ and a $k$-point mesh of $3 \times 2$ $\times 2$, were found to be sufficient for the bismuth and $\mathrm{PbI}_{2}-\mathrm{dppz}$ compounds. For $\mathrm{PbI}_{2}$-dppn, a cutoff of $400 \mathrm{eV}$ and a k-point mesh of 2 $\times 2 \times 1$ was sufficient. In all cases, the structures were considered converged when the forces on each atom totaled less than $0.01 \mathrm{eV} \cdot \AA^{-1}$.

\section{ASSOCIATED CONTENT}

\section{S Supporting Information}

The Supporting Information is available free of charge on the ACS Publications website at DOI: 10.1021/acs.inorgchem.5b02749.

Fifteen figures and six tables showing powder XRD of samples after exposure to air, photographs of films of the reported compounds, band structure calculations, and partial densities of states derived from DFT calculations (PDF) Crystallographic file for 2 (CIF)

Crystallographic file for 4 (CIF)

Crystallographic file for 1 (CIF)

Crystallographic file for 3 (CIF)

\section{AUTHOR INFORMATION}

\section{Corresponding Author}

*E-mail: r.palgrave@ucl.ac.uk.

\section{Author Contributions}

The manuscript was written through contributions of all authors. All authors have given approval to the final version of the manuscript.

C.N.S. and A.M.G. contributed equally.

\section{Funding}

We acknowledge funding from the EPSRC SUPERGEN Supersolar Hub (EP/J017361/1). Z.S. acknowledges a Royal Society of Chemistry Summer Bursary. This work made use of the ARCHER UK National Supercomputing Service (http:// www.archer.ac.uk), via the membership of the UK's HPC Materials Chemistry Consortium, which is funded by EPSRC (EP/L000202). This work was supported by EPSRC (EP/ N01572X/1). C.N.S. acknowledges the UCL Department of Chemistry for providing a DTA studentship. A.M.G. acknowl- 
edges Diamond Light Source for the co-sponsorship of a studentship on the EPSRC Centre for Doctoral Training in Molecular Modelling and Materials Science (EP/L015862/1). A.M.G. acknowledges Diamond Light Source and the M3S CDT at UCL for the cosponsorship of a studentship.

\section{Notes}

The authors declare no competing financial interest.

\section{ACKNOWLEDGMENTS}

R.G.P. and D.O.S. acknowledge the Materials Design Network. D.O.S., C.N.S., and A.M.G. acknowledge the use of the Archer U.K. National Supercomputing Service (http://www.archer.ac. uk), via our membership in the U.K.'s HEC Materials Chemistry Consortium, which is funded by EPSRC (EP/ L000202).

\section{REFERENCES}

(1) Ginley, D.; Green, M. A.; Collins, R. MRS Bull. 2008, 33, 355.

(2) Kojima, A.; Teshima, K.; Shirai, Y.; Miyasaka, T. J. Am. Chem. Soc. 2009, 131, 6050.

(3) Green, M. A.; Emery, K.; Hishikawa, Y.; Warta, W.; Dunlop, E. D. Prog. Photovoltaics 2015, 23, 1.

(4) (a) Lee, M. M.; Teuscher, J.; Miyasaka, T.; Murakami, T. N.; Snaith, H. J. Science 2012, 338, 643. (b) Burschka, J.; Pellet, N.; Moon, S. J.; Humphry-Baker, R.; Gao, P.; Nazeeruddin, M. K.; Gratzel, M. Nature 2013, 499, 316. (c) Chang, J. A.; Im, S. H.; Lee, Y. H.; Kim, H. J.; Lim, C. S.; Heo, J. H.; Seok, S. I. Nano Lett. 2012, 12, 1863. (d) Im, J. H.; Lee, C. R.; Lee, J. W.; Park, S. W.; Park, N. G. Nanoscale 2011, 3, 4088.

(5) (a) Malinkiewicz, O.; Yella, A.; Lee, Y. H.; Espallargas, G. M.; Graetzel, M.; Nazeeruddin, M. K.; Bolink, H. J. Nat. Photonics 2014, 8, 128. (b) Liu, M. Z.; Johnston, M. B.; Snaith, H. J. Nature 2013, 501, 395.

(6) Kim, H. S.; Lee, C. R.; Im, J. H.; Lee, K. B.; Moehl, T.; Marchioro, A.; Moon, S. J.; Humphry-Baker, R.; Yum, J. H.; Moser, J. E.; Gratzel, M.; Park, N. G. Sci. Rep. 2012, 2, No. 591.

(7) (a) Knutson, J. L.; Martin, J. D.; Mitzi, D. B. Inorg. Chem. 2005, 44, 4699. (b) Wojciechowski, K.; Stranks, S. D.; Abate, A.; Sadoughi, G.; Sadhanala, A.; Kopidakis, N.; Rumbles, G.; Li, C. Z.; Friend, R. H.; Jen, A. K. Y.; Snaith, H. J. ACS Nano 2014, 8, 12701. (c) Jeon, N. J.; Noh, J. H.; Kim, Y. C.; Yang, W. S.; Ryu, S.; Il Seol, S. Nat. Mater. 2014, 13, 897.

(8) Walsh, A.; Scanlon, D. O.; Chen, S. Y.; Gong, X. G.; Wei, S. H. Angew. Chem., Int. Ed. 2015, 54, 1791.

(9) Heo, J. H.; Im, S. H.; Noh, J. H.; Mandal, T. N.; Lim, C. S.; Chang, J. A.; Lee, Y. H.; Kim, H. J.; Sarkar, A.; Nazeeruddin, M. K.; Gratzel, M.; Seok, S. I. Nat. Photonics 2013, 7, 486.

(10) (a) Xing, G. C.; Mathews, N.; Sun, S. Y.; Lim, S. S.; Lam, Y. M.; Gratzel, M.; Mhaisalkar, S.; Sum, T. C. Science 2013, 342, 344. (b) Stranks, S. D.; Eperon, G. E.; Grancini, G.; Menelaou, C.; Alcocer, M. J. P.; Leijtens, T.; Herz, L. M.; Petrozza, A.; Snaith, H. J. Science 2013, 342, 341.

(11) (a) Stoumpos, C. C.; Malliakas, C. D.; Kanatzidis, M. G. Inorg. Chem. 2013, 52, 9019. (b) Green, M. A.; Ho-Baillie, A.; Snaith, H. J. Nat. Photonics 2014, 8, 506.

(12) (a) Habisreutinger, S. N.; Leijtens, T.; Eperon, G. E.; Stranks, S. D.; Nicholas, R. J.; Snaith, H. J. Nano Lett. 2014, 14, 5561.

(b) Mosconi, E.; Azpiroz, J. M.; De Angelis, F. Chem. Mater. 2015, 27, 4885 .

(13) Young, J.; Rondinelli, J. M. Chem. Mater. 2013, 25, 4545.

(14) Noel, N. K.; Stranks, S. D.; Abate, A.; Wehrenfennig, C.; Guarnera, S.; Haghighirad, A. A.; Sadhanala, A.; Eperon, G. E.; Pathak, S. K.; Johnston, M. B.; Petrozza, A.; Herz, L. M.; Snaith, H. J. Energy Environ. Sci. 2014, 7, 3061.

(15) Kieslich, G.; Sun, S. J.; Cheetham, A. K. Chem. Sci. 2014, 5, 4712 .
(16) Pang, S. P.; Hu, H.; Zhang, J. L.; Lv, S. L.; Yu, Y. M.; Wei, F.; Qin, T. S.; Xu, H. X.; Liu, Z. H.; Cui, G. L. Chem. Mater. 2014, 26, 1485.

(17) (a) Im, J. H.; Chung, J.; Kim, S. J.; Park, N. G. Nanoscale Res. Lett. 2012, 7, No. 353. (b) Randall, J. J., Jr.; Katz, L. Acta Crystallogr. 1959, 12, 519. (c) Fan, L.-Q.; Wu, J.-H. Acta Crystallogr., Sect. E: Struct. Rep. Online 2007, 63, i189.

(18) (a) Mousdis, G. A.; Gionis, V.; Papavassiliou, G. C.; Raptopoulou, C. P.; Terzis, A. J. Mater. Chem. 1998, 8, 2259. (b) Mitzi, D. B.; Wang, S.; Feild, C. A.; Chess, C. A.; Guloy, A. M. Science 1995, 267, 1473. (c) Mitzi, D. B. J. Chem. Soc., Dalton Trans. 2001, 1.

(19) Jeon, N. J.; Noh, J. H.; Yang, W. S.; Kim, Y. C.; Ryu, S.; Seo, J.; Seok, S. I. Nature 2015, 517, 476.

(20) Walsh, A. J. Phys. Chem. C 2015, 119, 5755.

(21) Takada, J.; Awaji, H.; Koshioka, M.; Nakajima, A.; Nevin, W. A. Appl. Phys. Lett. 1992, 61, 2184.

(22) (a) Brivio, F.; Walker, A. B.; Walsh, A. APL Mater. 2013, 1, No. 042111. (b) Leguy, A. M. A.; Frost, J. M.; McMahon, A. P.; Sakai, V. G.; Kockelmann, W.; Law, C.; Li, X. E.; Foglia, F.; Walsh, A.; O’Regan, B. C.; Nelson, J.; Cabral, J. T.; Barnes, P. R. F. Nat. Commun. 2015, 6, No. 7124. (c) Jackson, N. E.; Savoie, B. M.; Marks, T. J.; Chen, L. X.; Ratner, M. A. J. Phys. Chem. Lett. 2015, 6, 77.

(23) (a) Zhou, H. P.; Chen, Q.; Li, G.; Luo, S.; Song, T. B.; Duan, H. S.; Hong, Z. R.; You, J. B.; Liu, Y. S.; Yang, Y. Science 2014, 345, 542. (b) Boix, P. P.; Agarwala, S.; Koh, T. M.; Mathews, N.; Mhaisalkar, S. G. J. Phys. Chem. Lett. 2015, 6, 898. (c) Pellet, N.; Gao, P.; Gregori, G.; Yang, T. Y.; Nazeeruddin, M. K.; Maier, J.; Gratzel, M. Angew. Chem., Int. Ed. 2014, 53, 3151.

(24) Safdari, M.; Fischer, A.; Xu, B.; Kloo, L.; Gardner, J. M. J. Mater. Chem. A 2015, 3, 9201.

(25) Bronstein, H.; Frost, J. M.; Hadipour, A.; Kim, Y.; Nielsen, C. B.; Ashraf, R. S.; Rand, B. P.; Watkins, S.; McCulloch, I. Chem. Mater. 2013, 25, 277.

(26) Sanchez, C.; Boissiere, C.; Cassaignon, S.; Chaneac, C.; Durupthy, O.; Faustini, M.; Grosso, D.; Laberty-Robert, C.; Nicole, L.; Portehault, D.; Ribot, F.; Rozes, L.; Sassoye, C. Chem. Mater. 2014, 26, 221.

(27) (a) Zhu, H. G.; Xu, Y.; Yu, Z.; Wu, Q. J.; Fun, H. K.; You, X. Z. Polyhedron 1999, 18, 3491. (b) Harrowfield, J. M.; Miyamae, H.; Skelton, B. W.; Soudi, A. A.; White, A. H. Aust. J. Chem. 1996, 49, 1029.

(28) Reger, D. L.; Huff, M. F.; Rheingold, A. L.; Haggerty, B. S. J. Am. Chem. Soc. 1992, 114, 579.

(29) Shimoni-Livny, L.; Glusker, J. P.; Bock, C. W. Inorg. Chem. 1998, 37, 1853.

(30) Shi, Y. J.; Jiang, G. Q.; Zhang, Y. H.; You, X. Z. Appl. Organomet. Chem. 2004, 18, 89.

(31) Zhang, S. F.; Lin, J. G.; Liu, J.; Xie, S. B.; Liu, J. B.; Li, H. H.; Chen, Z. R. Chin. J. Struct. Chem. 2014, 33, 549.

(32) Lin, H.; Huang, C. P.; Li, W.; Ni, C.; Shah, S. I.; Tseng, Y. H. Appl. Catal., B 2006, 68, 1.

(33) Ahuja, R.; Arwin, H.; da Silva, A. F.; Persson, C.; OsorioGuillen, J. M.; de Almeida, J. S.; Araujo, C. M.; Veje, E.; Veissid, N.; An, C. Y.; Pepe, I.; Johansson, B. J. Appl. Phys. 2002, 92, 7219.

(34) Podraza, N. J.; Qiu, W.; Hinojosa, B. B.; Xu, H. X.; Motyka, M. A.; Phillpot, S. R.; Baciak, J. E.; Trolier-McKinstry, S.; Nino, J. C. J. Appl. Phys. 2013, 114, No. 033110.

(35) Borriello, I.; Cantele, G.; Ninno, D. Phys. Rev. B: Condens. Matter Mater. Phys. 2008, 77, No. 235214.

(36) (a) Wang, S. M.; Mitzi, D. B.; Feild, C. A.; Guloy, A. J. Am. Chem. Soc. 1995, 117, 5297. (b) Mitzi, D. B.; Liang, K. N.; Wang, S. M. Inorg. Chem. 1998, 37, 321.

(37) Shockley, W.; Queisser, H. J. J. Appl. Phys. 1961, 32, 510.

(38) Chelvayohan, M.; Mee, C. H. B. J. Phys. C: Solid State Phys. 1982, 15, 2305

(39) Mazzio, K. A.; Luscombe, C. K. Chem. Soc. Rev. 2015, 44, 78.

(40) Even, J.; Pedesseau, L.; Jancu, J. M.; Katan, C. J. Phys. Chem. Lett. 2013, 4, 2999. 
(41) (a) Liu, J. J.; Guan, Y. F.; Jiao, C.; Lin, M. J.; Huang, C. C.; Dai, W. X. Dalton Trans. 2015, 44, 5957. (b) Fujisawa, J.; Ishihara, T. Phys. Rev. B: Condens. Matter Mater. Phys. 2004, 70, No. 205330.

(42) Heidel, T. D.; Hochbaum, D.; Sussman, J. M.; Singh, V.; Bahlke, M. E.; Hiromi, I.; Lee, J.; Baldo, M. A. J. Appl. Phys. 2011, 109, No. 104502 .

(43) Giorgi, G.; Fujisawa, J. I.; Segawa, H.; Yamashita, K. J. Phys. Chem. Lett. 2013, 4, 4213.

(44) Varley, J. B.; Janotti, A.; Singh, A. K.; Van de Walle, C. G. Phys. Rev. B: Condens. Matter Mater. Phys. 2009, 79, No. 245206.

(45) Dolomanov, O. V.; Bourhis, L. J.; Gildea, R. J.; Howard, J. A. K.; Puschmann, H. J. Appl. Crystallogr. 2009, 42, 339.

(46) Sheldrick, G. M. Acta Crystallogr., Sect. A: Found. Adv. 2015, 71, 3.

(47) Sheldrick, G. M. Acta Crystallogr., Sect. A: Found. Crystallogr. 2008, 64, 112.

(48) (a) Palatinus, L.; Chapuis, G. J. Appl. Crystallogr. 2007, 40, 786. (b) Palatinus, L.; Prathapa, S. J.; van Smaalen, S. J. Appl. Crystallogr. 2012, 45, 575. (c) Palatinus, L.; van der Lee, A. J. Appl. Crystallogr. 2008, 41, 975.

(49) (a) Kresse, G.; Hafner, J. Phys. Rev. B: Condens. Matter Mater. Phys. 1993, 47, 558. (b) Kresse, G.; Hafner, J. Phys. Rev. B: Condens. Matter Mater. Phys. 1994, 49, 14251. (c) Kresse, G.; Furthmuller, J. Phys. Rev. B: Condens. Matter Mater. Phys. 1996, 54, 11169. (d) Kresse, G.; Furthmuller, J. Comput. Mater. Sci. 1996, 6, 15.

(50) Kresse, G. Phys. Rev. B: Condens. Matter Mater. Phys. 1999, 59, 1758

(51) Perdew, J. P.; Ruzsinszky, A.; Csonka, G. I.; Vydrov, O. A.; Scuseria, G. E.; Constantin, L. A.; Zhou, X. L.; Burke, K. Phys. Rev. Lett. 2008, 100, No. 136406.

(52) Perdew, J. P.; Burke, K.; Ernzerhof, M. Phys. Rev. Lett. 1996, 77, 3865.

(53) Krukau, A. V.; Vydrov, O. A.; Izmaylov, A. F.; Scuseria, G. E. J. Chem. Phys. 2006, 125, No. 224106.

(54) (a) Bhachu, D. S.; Scanlon, D. O.; Saban, E. J.; Bronstein, H.; Parkin, I. P.; Carmalt, C. J.; Palgrave, R. G. J. Mater. Chem. A 2015, 3, 9071. (b) Butler, K. T.; Frost, J. M.; Walsh, A. Mater. Horiz. 2015, 2, 228.

(55) Savory, C. N.; Palgrave, R. G.; Bronstein, H.; Scanlon, D. O. Sci. Rep. 2016, 6, 20626.

(56) (a) Temple, D. J.; Kehoe, A. B.; Allen, J. P.; Watson, G. W.; Scanlon, D. O. J. Phys. Chem. C 2012, 116, 7334. (b) Janesko, B. G.; Henderson, T. M.; Scuseria, G. E. Phys. Chem. Chem. Phys. 2009, 11, 443.

(57) Ganose, A. M.; Savory, C. N.; Scanlon, D. O. J. Phys. Chem. Lett. 2015, 6, 4594 . 